\title{
Evaluation of Total Phenolic Compound and Cytotoxic Activity of Clinacanthus nutans
}

PIYA KOSAI, KANJANA SIRISIDTHI AND WANNEE JIRAUNGKOORSKUL*

Department of Pathobiology, Faculty of Science, Mahidol University, Ratchathewi, Bangkok 10400, Thailand

Kosai, et al.: Phenolic and Cytotoxicity of Clinacanthus nutans

\begin{abstract}
Clinacanthus nutans leaves were extracted in distilled water at $0.5,1,3,5$ and $24 \mathrm{~h}$. The plant extracts were determined the highest amount of total phenolic compound and used for evaluating the cytotoxicity test. The median (LC50) and 90\% lethal concentration (LC90) against Artemia salina at varied concentrations of this plant extractions as $0,400,800,1600,3200,6400$ and $12800 \mu \mathrm{g} / \mathrm{ml}$ were evaluated within $24 \mathrm{~h}$ exposure. The result revealed that the total phenolic compound measurements in each time extraction were $34.68 \pm 3.17$, $46.71 \pm 9.31,36.13 \pm 7.06,26.53 \pm 8.83$ and $30.15 \pm 3.09 \mathrm{mg}$ gallic acid equivalent per $\mathrm{g}$ of extract, respectively. Due to the highest amount of total phenolic compound, the $1 \mathrm{~h}$ aqueous extract of $C$. nutans leaf expressed the $24 \mathrm{~h} \mathrm{LC50}$ and LC90 values against $A$. salina were 7,151.1 and $12,008.7 \mu \mathrm{g} / \mathrm{ml}$, respectively.
\end{abstract}

Key words: Antioxidant, Artemia salina, brine shrimp, Clinacanthus nutans, total phenolic compound

The famous saying "there is good and bad in everything" implies to the plants too. The good side is that it has antioxidant substances and the bad side is the toxicity. Medicinal plant parts including roots, leaves, stems, barks, flowers and fruit have been used in virtually all cultures as a source of medicine because of their pharmacological activities and antioxidant properties ${ }^{[1]}$. They are commonly rich in phenolic compounds such as flavonoids, phenolic acids, tannins, coumarins, and lignins ${ }^{[2]}$. Clinacanthus nutans has been widely used as a traditional medicinal plant in Asia for treating skin rashes, bugs and snake chomps, sores brought on by herpes simplex infection, diabetes mellitus, fever and diuretics $^{[3]}$.

C. nutans is a well-known antisnake venom and antiviral agent ${ }^{[4]}$. It belongs to the family Acanthaceae which is a large family, comprised of about 250 genera and 2,500 species distributed in the world ${ }^{[5]}$. The genus Clinacanthus comprises two species, C. nutans (Burm. f.) Lindau and C. spirei Benoist, and synonymous with Justicia nutans, J. fulgida, $C$. burmanni, C. siamensis ${ }^{[4]}$. C. nutans is also known as giro de flores, cocodrilo flor, e zui hua (Chinese), yudunsou (Japanese), yōuduncho (Korean), ki tajam, dandang gendis (Indonesian), belalai gajah, sabah snake grass (Malay), ki tajam (Sunda), saled pangpon tua mea, phaya yor, phak man kai, phak lin khiat (Thai), and mảnh cộng; lá cầm; bìm bịp; xuoơng $k h i$ (Vietnamese) $)^{[6-8]}$.

\section{${ }^{*}$ Address for correspondence}

E-mail: wannee.jir@mahidol.ac.th
C. nutans is a shrub of 1-3 m height with pubescent branches. Leaves are pale green, simple, opposite, narrowly elliptic oblong with acute apex size 2.5$13.0 \mathrm{~cm}$ long and $0.5-1.5 \mathrm{~cm}$ wide. The leaf base are obtuse rounded or truncate and often oblique. In addition, it has about 6-7 pairs side of veins. The stem is stiffly straight along with internodes and vertical strips along the stem. Flowers are dense at the peak of the branch, has glandular-pubescent calyx around $3.5 \mathrm{~cm}$ with dull red, green base and yellow streaks. As the flowers are in dense cymes at the top of the branches and often terminating drooping horizontal ${ }^{[4]}$. Stamens are exert from the corolla. The ovary is packed into two cells and each cell contains two ovules ${ }^{[9]}$. Phytochemical analysis has shown that $C$. nutans contains several kinds of clinamide derivatives $^{[10]}$, alkaloids ${ }^{[11]}$, chlorophyll ${ }^{[12]}$, flavonoids ${ }^{[13]}$, phenolic compounds ${ }^{[14]}$.

Medicinal plants have gained huge interests from researchers around the world because of their positive biological activity ${ }^{[15]}$. However, there is still not much data available about the toxicity of medical plants. For this reason, this experiment is set out to observe the cytotoxic effect of Clinacanthus nutans extract against Artemia salina. The brine shrimp lethality assay is a widely used method used to indicate general toxicity because of its simplicity ${ }^{[16-18]}$. The findings from this study would give basic contributions for the development of new treatments for health providers.

Fresh, mature, green leaves of $C$. nutans were randomly collected in Surat Thani Province, Southern part of Thailand. The voucher specimen was numbered and kept in our research laboratory 
for the further reference. The leaves were washed with tap water and air dried in shade for $24 \mathrm{~h}$ and dried in a hot air oven at $70^{\circ}$ for $6 \mathrm{~h}$, and crushed with a blender (fig.1). The extraction procedure was determined by the method of Pavananundt, et al. ${ }^{[19]}$ with modifications. Five grams of leaf powder was extracted with $100 \mathrm{ml}$ of distilled water on a shaker at $180 \mathrm{rpm}$ for $0.5,1,3,5$, and $24 \mathrm{~h}$ at room temperature. The whole mixture was then filtered through a fresh gauge plug, and centrifuged at $4000 \mathrm{rpm}$ for $10 \mathrm{~min}$ Finally, supernatant was filtered with a Whatman number 1 filter paper, the clear filtrate used as a stock solution for total phenolic compound measurement and bioassay experiment.

Total phenolic compound was determined using Folin-Ciocalteu reagent according to methods of Jiraungkoorskul ${ }^{[20]}$ and Mcdonald, et al. ${ }^{[21]}$ with modifications. Briefly, the $50 \mu \mathrm{l}$ of the extraction in each time $(0.5,1,3,5$ and $24 \mathrm{~h})$ was mixed with $250 \mu \mathrm{l}$ of $10 \%$ Folin-Ciocalteus and $200 \mu \mathrm{l}$ of 0.7 $\mathrm{M}$ sodium carbonate then add distilled water until $5 \mathrm{ml}$ and incubated at room temperature for $2 \mathrm{~h}$ in the dark room. The mixture was measured at $724 \mathrm{~nm}$ by using a spectrophotometer. Quantification was based on the standard curve of the gallic acid and expressed as gallic acid equivalent (GAE) using the following linear equation based on the calibration curve as shown in this equation $\left(\mathrm{OD}=8314.1 \mathrm{C}^{2}-\right.$ 2631.6C+75.261), where OD was the absorbance and $\mathrm{C}$ was concentration as GAE.

The brine shrimp lethality assay was assigned to determine the cytotoxic effect of plant extract. It followed the method by Meyer, et al. ${ }^{[16]}$. Due to the highest amount of total phenolic compound, the required concentrations $(0,400,800,1600,3200$, 6400 and $12800 \mu \mathrm{g} / \mathrm{ml}$ ) were prepared through mixing up of the $1 \mathrm{~h}$ extraction with variable amounts of $2.5 \% \mathrm{NaCl}$. Ten $A$. salina were added into five replicates of each concentration of the leaf extract. The bioassay was maintained at $26 \pm 1^{\circ}$ throughout the test. The mortality was recorded for a maximum of $24 \mathrm{~h}$ of exposure. They were considered dead or moribund if they stopped moving for a prolonged

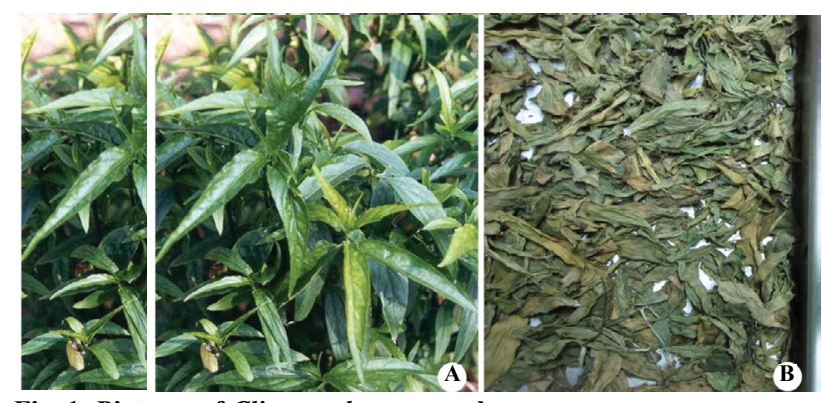

Fig. 1: Pictures of Clinacanthus nutans leaves.

Clinacanthus nutans in fresh (A) and dry (B) leaves period even after gentle probing with a small spatula. The $\mathrm{LC}_{50}$ was analyzed by the probit method of Finney ${ }^{[22]}$ using the SPSS 18.0 (Statistical Package of Social Sciences) software. It estimated the lethal concentration and the slope of the regression line with its confidence interval $(\mathrm{P} \leq 0.05)$.

The total phenolic compound from leaves of $C$. nutans measurement in each time extraction $0.5,1,3$, 5 and 24 h were $34.68 \pm 3.17,46.71 \pm 9.31,36.13 \pm 7.06$, $26.53 \pm 8.83$ and $30.15 \pm 3.09 \mathrm{mg} / \mathrm{g} \mathrm{GAE}$, respectively (fig.2). The result of brine shrimp assay was expressed in percentage of mortality. The dose dependent mortality was observed, as the rate of mortality (y) was positively correlated with the concentration (x) of the leaf extract as evident from established regression equations $(y=121.44 x+1079.1)$. The percentage mortality increased as the concentration of aqueous extract of $C$. nutans increased. The $1 \mathrm{~h}$ aqueous extract of $C$. nutans leaf expressed the 24-h $\mathrm{LC}_{50}$ and $\mathrm{LC}_{90}$ values in $A$. salina were 7151.1 and $12008.7 \mu \mathrm{g} / \mathrm{ml}$, respectively. C. nutans showed a significant effect against brine shrimp. The correlation (R2) between concentration and mortality was 0.9767 (fig.3).

There is an increasing interest in the supplementation of antioxidants from a natural plant ${ }^{[23]}$. To avoid any solvent effect, the aqueous solvent was used to extract $C$. nutans in the present study. Literature

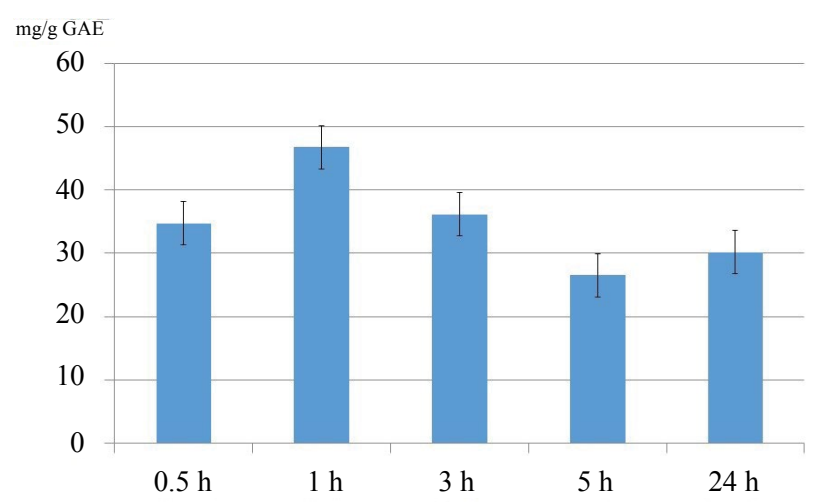

Fig. 2: Total phenolic compounds of Clinacanthus nutans leaf extract

Concentration of total phenolic compounds in the leaf extract of Clinacanthus nutans expressed as $\mathrm{mg} / \mathrm{g}$ GAE at each time interval

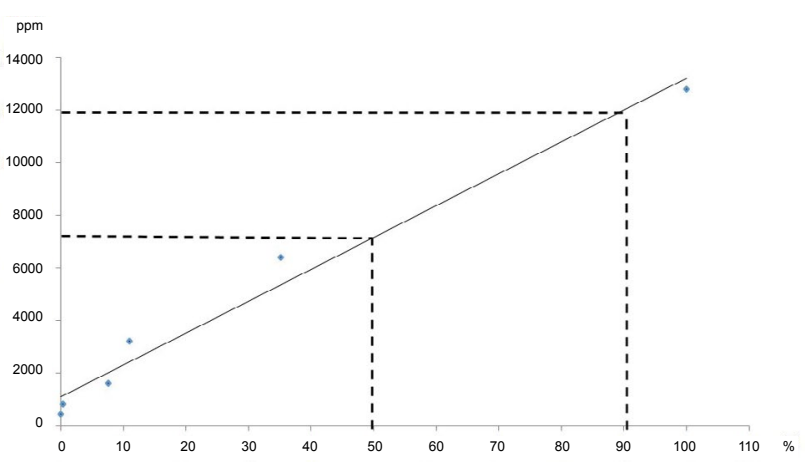

Fig. 3: The correlation between concentration and mortality. The relationship between the percentage of Artemia salina dead (X-axis) and Clinacanthus nutans leaf extract concentration (Y-axis) 
survey has revealed a direct relationship between antioxidant activity and total phenolic content ${ }^{[24,25]}$. The present result revealed that the total phenolic compound measurements in $0.5,1,3,5$ and $24 \mathrm{~h}$ extraction were $34.68 \pm 3.17,46.71 \pm 9.31,36.13 \pm 7.06$, $26.53 \pm 8.83$ and $30.15 \pm 3.09 \mathrm{mg} / \mathrm{g} \mathrm{GAE}$, respectively. These results were in agreement with earlier reports. Thongrakard and Tencomnao ${ }^{[26]}$ in Thailand extracted $C$. nutans leaves with ethanol at 1:5 (w/v) for $48 \mathrm{~h}$ and reported the total phenolic compound measurement was $4.67 \mathrm{mg} \mathrm{GAE} / \mathrm{g}$ of extract. Yuann, et al. ${ }^{[27]}$ in Taiwan extracted $1 \mathrm{~g}$ of $C$. nutans leaves with $5 \mathrm{ml} \mathrm{70 \%} \mathrm{ethanol} \mathrm{for} 20$ mins and reported the total phenolic compound measurement was $23.5 \mathrm{mg}$ GAE/g of extract. Lee, et al..$^{[28]}$ in Malaysia extracted $20 \mathrm{~g}$ of $C$. nutans leaves and stems with $500 \mathrm{ml}$ absolute methanol for an hour and reported the total phenolic compound in stem and leave were 0.12 and $2.68 \mathrm{mg} \mathrm{GAE} / \mathrm{g}$ of extract, respectively. Wong, et al. ${ }^{[29]}$ in Malaysia extracted $C$. nutans leaves with distilled water at 1:19 (w/v) for an hour and reported the total phenolic compound measurement was 14.70 mg GAE/g of extract.

Using brine shrimp lethality bioassay the tested cytotoxic activity of the aqueous extract of leaves of $C$. nutans were found to show a little toxicity as expressed the $24 \mathrm{~h} \mathrm{LC}_{50}$ and $\mathrm{LC}_{90}$ values in $A$. salina were 7151.1 and $12008.7 \mu \mathrm{g} / \mathrm{ml}$, respectively. Each of the different concentrations samples showed different mortality rates. When graphed, the concentrations versus mortality percentage showed an approximate linear correlation. These results were not in agreement with earlier reports because most of the studies on $C$. nutans cytotoxicity have been done using crude extracts. Various researchers have reported the cytotoxicity of $C$. nutans in different doses, time and solvent extraction. Haetrakul, et $a l .{ }^{[30]}$ found that $C$. nutans plant extract at 0.005 and $0.01 \%$ damaged Koi Fin cell line and for non-toxic concentration of this plant was $0.001 \%$. Kunsorn, et al. ${ }^{[4]}$ reported the $\mathrm{IC}_{50}$ values of $C$. nutans extracted with $n$-hexane, dichloromethane and methanol against herpes simplex virus-1 were $32.05 \pm 3.63$, $44.50 \pm 2.66$, and $64.93 \pm 7.00 \mu \mathrm{g} / \mathrm{ml}$, respectively. Ping et al.$^{[31]}$ reported that the repeatedly dosing of $C$. nutans extract at $0.3,0.6$ and $0.9 \mathrm{~g} / \mathrm{kg}$ up to 14 days was proven safe in male Sprague Dawley rats without causing any adverse effects and organ damages in rats. Arullappan, et al. ${ }^{[7]}$ reported that the petroleum ether extracts of $C$. nutans demonstrated the strongest cytotoxic activity against HeLa and K-562 cell lines with $\mathrm{IC}_{50}$ of 18.0 and $20.0 \mu \mathrm{g} / \mathrm{ml}$, respectively. This activity could be explained by the phenols and flavonoids present in the extract. There are the reports in the literature describing the antimicrobial activity correlated high content of phenolics and flavonoids in C. nutans leave extract ${ }^{[7,32]}$.

In conclusion, the aqueous extract of $C$. nutans can be alternatively used as the natural product. However, further studies are necessary to find out what the active substances are and how they perform or the mechanism of them in the target species.

\section{ACKNOWLEDGEMENTS}

The authors thank the members of the Fish Research Unit, Department of Pathobiology, Faculty of Science, Mahidol University, Bangkok, for the technical support in their laboratory.

\section{FINANCIAL ASSISTANCE}

This study was funded by the Thailand Research Fund and the Commission on Higher Education: Research Grant for Mid-Career University Faculty.

\section{CONFLICT OF INTERESTS}

None declared.

\section{REFERENCES}

1. Petrovska BB. Historical review of medicinal plants' usage. Pharmacogn Rev 2012;6:1-5.

2. Surveswaran S, Cai YZ, Corke H, Sun M. Systematic evaluation of natural phenolic antioxidants from 133 Indian medicinal plants. Food Chem 2007;102:938-53.

3. Tuntiwachwuttikul P, Pootaeng-on Y, Phansa P, Taylor WC. Cerebrosides and a monoacylmonogalactosyglycerol from Clinacanthus nutans. Chem Pharm Bull 2004;52:27-32.

4. Kunsorn P, Ruangrungsi N, Lipipun V, Khanboon A, Rungsihirunrat $\mathrm{K}$. The identities and anti-herpes simplex virus activity of Clinacanthus nutans and Clinacanthus siamensis. Asian Pac J Trop Biomed 2013;3:284-90.

5. McDade LA, Daniel TF, Kiel CA. Toward a comprehensive understanding of phylogenetic relationships among lineages of Acanthaceae s.l. (Lamiales). Am J Bot 2008;95:1136-52.

6. Watson RR, Preedy VR. Botanical Medicine in Clinical Practice. Trowbridge: Cromwell Press; 2008. p. 819-20.

7. Arullappan S, Rajamanickam P, Thevar N, Kodimani CC. In vitro screening of cytotoxic, antimicrobial and antioxidant activities of Clinacanthus nutans (Acanthaceae) leaf extracts. Trop J Pharm Res 2014;13:1455-61.

8. Aslam MS, Ahmad MS, Mamat AS. A review on phytochemical constituents and pharmacological activities of Clinacanthus nutans. Int J Pharm Pharm Sci 2015;7:30-3.

9. Ali RM, Samah ZA, Mustapha NM, Hussein N. ASEAN Herbal and Medicinal Plants. Jakarta: ASEAN Secretariat; 2010. p. 284-5.

10. Tu SF, Liu RH, Cheng YB, Hsu YM, Du YC, El-Shazly M, et al. Chemical constituents and bioactivities of Clinacanthus nutans aerial parts. Molecules 2014;19:20382-90.

11. Ho SY, Tiew WP, Priya M, Mohamed SAS, Gabriel AA. Phytochemical analysis and antibacterial activity of 
methanolic extract of Clinacanthus nutans leaf. Int J Drug Dev Res 2013;5:229-33.

12. Sakdarat S, Shuyprom A, Pientong C, Ekalaksananan $\mathrm{T}$, Thongchai S. Bioactive constituents from the leaves of Clinacanthus nutans Lindau. Bioorg Med Chem 2009; 17:1857-60.

13. Chelyn JL, Omar MH, Mohd Yousof NSA, Ranggasamy R, Wasiman MU, Ismail Z. Analysis of flavone c-glycosides in the leaves of Clinacanthus nutans (Burm. f.) Lindau by HPTLC and HPLC-UV/DAD. Sci World J 2014;724267:1-6.

14. Ghasemzadeh A, Nasiri A, Jaafar HZE, Baghdadi A, Ahmad I. Changes in phytochemical synthesis, chalcone synthase activity and pharmaceutical qualities of sabah snake grass (Clinacanthus nutans L.) in relation to plant age. Molecules 2014;19:17632-48.

15. Gurib-Fakim A. Medicinal plants: traditions of yesterday and drugs of tomorrow. Mol Aspects Med 2006;27:1-93.

16. Meyer BN, Ferrigni NR, Putnam JB, Jacobsen LB, Nichols DE, McLaughlin JL. Brine shrimp: A convenient general bioassay for active plant constituents. Planta Med 1982;45:31-4.

17. Pimentel Montanher AB, Pizzolatti MG, Costa Brighente IM. An application of the brine shrimp bioassay for general screening of Brazilian medicinal plants. Acta Farm Bonaerense 2002;21:175-8.

18. Wu C. An important player in brine shrimp lethality bioassay: The solvent. J Adv Pharm Technol Res 2014;5:57-8.

19. Pavananundt $P$, Jiraungkoorskul K, Kosai $P$, Jiraungkoorskul W. Larvicidal properties of Cassia siamea leaf against Aedes aegypti larvae. Int J Mod Agric 2013;2:1-8.

20. Jiraungkoorskul W. Larvicidal and histopathological effects of Andrographis paniculata leaf extract against Culex quinquefasciatus larva. Walailak J Sci Technol 2016;13:133-40.

21. Mcdonald S, Prenzler PD, Antolovich M, Robards K. Phenolic content and antioxidant activity of olive oil extracts. Food Chem 2001;73:73-84.

22. Finney DJ. Probit analysis. Cambridge: Cambridge University Press; 1971. p. 88-99.

23. Yanishlieva NV, Marinova E, Pokorny J. Natural antioxidans from herbs and spices. Eur J Lipid Sci Tech 2006;108:776-93.
24. Conforti F, Sosa S, Marrelli M, Menichini F, Statti GA, Uzunov D, et al. The protective ability of Mediterranean dietary plants against the oxidative damage: The role of radical oxygen species in inflammation and the polyphenol, flavonoid and sterol contents. Food Chem 2009;112:587-94.

25. Kumar A, Kaur R, Arora S. Free radical scavenging potential of some Indian medicinal plants. J Med Plants Res 2010;4:2034-42.

26. Thongrakard V, Tencomnao T. Modulatory effects of Thai medicinal plant extract on proinflammatory cytokinesinduced apoptosis in human keratinocyte $\mathrm{HaCaT}$ cells. Afr $\mathrm{J}$ Biotech 2010;9:4999-5003.

27. Yuann JMP Wang JS, Jian HL, Lin CC, Liang JY. Effects of Clinacanthus nutans (Burm.f) Lindau leaf extracts on protection of plasmid DNA from riboflavin photoreaction. MC-Trans Biotech 2012;4:45-58.

28. Lee SY, Mediani A, Nur Ashikin AH, Azliana ABS, Abas F. Antioxidant and $\alpha$-glucosidase inhibitory activities of the leaf and stem of selected traditional medicinal plants. Int Food Res J 2014;21:165-72.

29. Wong FC, Yong AL, Ting EPS, Khoo SC, Ong HC, Chai TT. Antioxidant, metal chelating, anti-glucosidase activities and phytochemical analysis of selected tropical medicinal plants. Iranian J Pharm Res 2014;13:1409-15.

30. Haetrakul T, Tangtrongpiros J, Suthamnajpong N, Chansue N. Cytotoxicity concentration of acyclovir and Clinacanthus nutans (Burm. f.) Lindau. extract to koi fin cell line. Processing $9^{\text {th }}$ Chulalongkorn University Veterinary Science Annual Conference, 2010. p.108.

31. Ping XW, Akowuah GA, Chin JH. Evaluation of the subacute oral toxic effect of methanol extract of Clinacanthus nutans leaves in rats. J Acute Dis 2013;2:29-32.

32. Yang HS, Peng TW, Madhavan P, Abdul Shukkoor MS, Akowuah GA. Phytochemical analysis and antibacterial activity of methanolic extract of Clinacanthus nutans leaf. Int J Drug Dev Res 2013;5:349-55. 